\title{
Stage II Penile Cancer AJCC v7
}

National Cancer Institute

\section{Source}

National Cancer Institute. Stage II Penile Cancer AJCC v7. NCI Thesaurus. Code C89196.

Stage II includes: (T1b, N0, M0); (T2, N0, M0); (T3, N0, M0). T1 b: Tumor invades subepithelial connective tissue with lymph vascular invasion or is poorly differentiated. 12 : Tumor invades corpus spongiosum or cavernosum. T3: Tumor invades urethra. cNO: No palpable or visibly enlarged inguinal lymph nodes. pNO: No regional lymph node metastasis. M0: No distant metastasis. (AJCC 7th ed.) 